https://doi.org/10.21670/ref.1903024

Artículos

\title{
Los migrantes regionales en Bahía Blanca, Argentina: Desafíos en el acceso a derechos sociales
}

\author{
Regional migrants in Bahía Blanca, Argentina: \\ Challenges in social rights access
}

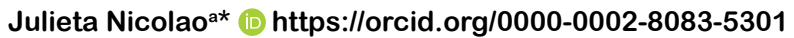

${ }^{a}$ Comisión de Investigaciones Científicas de la Provincia de Buenos Aires, Universidad Nacional del Centro de la Provincia de Buenos Aires, Centro de Estudios Interdisciplinarios en Problemáticas Internacionales y Locales, Provincia de Buenos Aires, Argentina, correo electrónico: nicolao_j@ yahoo.com.ar

\section{Resumen}

Este artículo tiene como objetivo analizar la inserción social de los migrantes regionales en el municipio de Bahía Blanca (Provincia de Buenos Aires, Argentina) con especial énfasis en su acceso a los derechos sociales reconocidos en la Ley de Migraciones $N^{\circ}$ 25.871, durante la etapa 2010-2018. A través

Recibido el 29 de septiembre de 2018. Aceptado el 14 de marzo de 2019. Publicado el 25 de marzo de 2019.

${ }^{*}$ Autor para correspondencia: Julieta Nicolao, correo electrónico nicolao_j@yahoo.com.ar

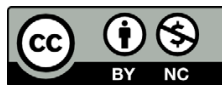

Esta obra está protegida bajo una Licencia Creative Commons Atribución-NoComercial 4.0 Internacional. de un estudio cualitativo, el trabajo identifica los nudos críticos en el acceso y utilidad de los recursos y servicios de salud y educación pública por parte de esta población, poniendo de relieve un conjunto de condiciones institucionales, culturales y sociales que limitan la realización práctica de la ciudadanía.

Palabras clave: migrantes regionales, nudos críticos, derechos sociales, municipio de Bahía Blanca, ciudadanía sustantiva.

\section{Abstract}

This article aims at analyzing the social insertion of regional migrants in the Bahía Blanca municipality (Buenos Aires province, Argentina), focusing in their access to the social rights recognized by the Migration Law 25.871, in the period between 2010-2018. Through a qualitative research, this paper identifies the "critical knots/issues" in the access and usefulness of health resources and services of migrants, highlighting a set of institutional, cultural and social conditions that limit the practical exercise of citizenship.

Keywords: regional migrants, critical issues/knots, social rights, Bahía Blanca municipality, substantive citizenship.

CÓMO CITAR: Nicolao, J. (2019). Los migrantes regionales en Bahía Blanca, Argentina: Desafíos en el acceso a derechos sociales [Regional migrants in Bahía Blanca, Argentina: Challenges in social rights access]. Estudios Fronterizos, 20, e024. doi:https://doi.org/10.21670/ref.1903024 


\section{Introducción}

Este artículo tiene como objetivo analizar la inserción social ${ }^{1}$ de los migrantes regionales en el municipio de Bahía Blanca (Provincia de Buenos Aires, Argentina), focalizando en su acceso a derechos sociales en el ámbito de la salud y la educación, reconocidos formalmente en la Ley de Migraciones $\mathrm{N}^{\circ} 25.871$ (2004).

Se entiende por migrantes regionales a aquellos procedentes de países sudamericanos, que forman parte de corrientes históricas a la República Argentina, y que arriban a Bahía Blanca desde países limítrofes (Chile, Bolivia, Paraguay) y otros de la región (Perú, y recientemente, Venezuela).

El hecho de concentrarse en este grupo migrante, responde a diversos factores entre los que figuran su peso numérico absoluto y relativo dentro de la migración que recibe el municipio; su impacto en la estructura económica y el mundo del trabajo; su condición de ciudadanos de países socios de Argentina en el Mercosur; ${ }^{2}$ y la previa constatación de su situación de mayor desprotección y vulneración de derechos en la región geográfica bajo estudio (Centro de Estudios Interdisciplinarios en Problemáticas Internacionales y Locales [CEIPIL], 2011, 2013a y 2013b; Instituto de Políticas Públicas en Derechos Humanos del Mercosur [IPPDH], Defensoría del Pueblo de la Provincia de Buenos Aires, 2014; Nicolao, 2013; Santamarina, 2016 y otros).

El trabajo se enmarca en los debates en torno a las brechas existentes entre el acceso a una ciudadanía formal y una ciudadanía sustantiva para las personas migrantes y a la construcción de esta última como un proceso que involucra a diferentes actores y niveles de acción que intervienen en el ajuste o ampliación entre ambas dimensiones.

El trabajo se sustenta en un análisis cualitativo, con utilización de estrategias de recolección de datos interactivas y no interactivas (Reyes y Hernández, 2008), considerando las contribuciones científicas precedentes sobre la temática. Entre las primeras, entrevistas semiestructuradas a informantes clave: migrantes miembros o líderes de organizaciones étnicas, referentes de organizaciones de la sociedad civil como Pastoral Migratoria, y de organismos públicos que median e intervienen en la accesibilidad a los derechos en los ámbitos referidos (educación y salud).

\footnotetext{
${ }^{1}$ Se emplea el término de inserción social para indicar las formas y modalidades en que la población migrante se incorpora a la sociedad receptora, desde una óptica integral que supera lo estrictamente socioeconómico. Se incluye dentro de esta categoría conceptual tanto su ingreso a los mercados de trabajo, como sus formas de contacto y vinculación con la institucionalidad actuante en el ámbito de la salud, la educación (salitas, hospitales, escuelas); el modo en que acceden a una vivienda o las pautas de ubicación socioespacial que asumen, sus formas de convivencia en los barrios y espacios públicos en general, así como su desarrollo sociocultural colectivo, entre otras dimensiones (Castaño, 2009; Thayer y Durán, 2015).

${ }^{2}$ El Mercado Común del Sur es un bloque regional integrado por Argentina, Brasil, Paraguay, Uruguay y Venezuela como Estados parte (aunque el último suspendido actualmente en los derechos y obligaciones inherentes a esta condición), y Bolivia, Chile, Colombia, Ecuador y Perú como Estados asociados.
} 
Se desarrollaron 60 entrevistas durante los meses de octubre de 2017 y mayo de $2018,{ }^{3}$ bajo una modalidad que combinó preguntas abiertas y focalizadas para la identificación de nudos críticos $^{4}$ a partir del relato discursivo (Guber, 2006). Las primeras dirigidas a lograr un planteamiento espontáneo de las experiencias y modalidades de incorporación individual o familiar de los migrantes a distintos ámbitos de la comunidad local, y las segundas reforzando los aspectos problemáticos emergentes en la primera, y solicitando una valoración específicamente direccionada sobre el acceso a los servicios de salud y educación.

Como estrategia no interactiva, se apeló al análisis documental de informes técnicos y documentos normativos diversos en los que se plasma la política migratoria.

$\mathrm{Al}$ tratarse de un estudio cualitativo, los resultados del análisis no revisten carácter tendencial. Se diferencia por tanto de otros de tenor demográfico y estadístico o de aquellos que abordan la inserción social de los migrantes desde perspectivas macroexplicativas (Varela, 2005). El aporte radica en la riqueza y complementación que ofrece a este tipo de investigaciones, los estudios que consideran la voz de los actores involucrados directa e indirectamente en la problemática estudiada.

La selección del periodo analizado (2010-2018), coincide en su inicio con el año en que el Poder Ejecutivo Nacional dictó la reglamentación de la citada ley de migraciones, estableciendo las directrices y actores institucionales responsables de aplicar cada una de sus disposiciones, lo cual permite contrastar este esquema formal con la práctica de los procedimientos y articulaciones exigidas en su implementación.

El artículo comienza vertiendo una serie de nociones teóricas y conceptuales en torno a los debates sobre el acceso de los migrantes a derechos sociales, su vinculación con el ejercicio de la ciudadanía sustantiva y el rol del nivel local para el análisis de dicha vinculación. Seguidamente, desde la óptica de la ciudadanía formal, se expone el marco legal que da contenido a la política migratoria argentina, y específicamente, al reconocimiento de derechos en el ámbito de la salud y la educación, prestando atención al rol que ocupa el nivel de gobierno local en dicho esquema regulatorio. En tercer término, se introduce el perfil migratorio del municipio de Bahía Blanca, en el contexto de la Provincia de Buenos Aires, Argentina, abordando aspectos tales como su peso demográfico, datos cuantitativos sobre población migrante, regiones y países

\footnotetext{
${ }^{3}$ El universo de entrevistados se conformó por 38 migrantes, líderes y/o miembros de organizaciones de migrantes como el Centro de Residentes Peruanos de Bahía Blanca, Centro Argentino Chileno "El Abrazo de Maipú", Asociación Boliviana de Bahía Blanca, Asociación de Residentes Paraguayos. Sumaron en conjunto 22 mujeres y 16 hombres, todos mayores de edad, originarios de Bolivia, Chile, Perú, Paraguay y también de Venezuela, careciendo esta última de estructura organizativa al momento de la presente investigación. Fueron contactados por registros oficiales municipales, de modo directo, o por sugerencia de instituciones. Por su parte, se entrevistaron 22 informantes no migrantes, entre los que se incluyen referentes de la Pastoral migratoria, de la Delegación de la Dirección Nacional de Migraciones de Bahía Blanca, el Cónsul General de Chile en Bahía Blanca, y un conjunto de agentes públicos del ámbito de la salud y la educación, con perfiles profesionales diferenciados (docentes, directivos, orientadores educacionales, profesionales de la salud, enfermeros, trabajadores sociales). En este caso, los criterios de selección se basaron en la denominada "muestra de casos sumamente importantes para el problema analizado" (Hernández, Fernández-Collado y Baptista, 2006, p. 567): p. e., trabajadores del sector educativo de dos instituciones con elevada matrícula de migrantes (primaria y secundaria) y un centro de salud localizado en un barrio en el que se concentra población migrante regional.

${ }^{4}$ Concepto empleado para referir al conjunto de situaciones o elementos que obstaculizan, demoran o problematizan el desarrollo eficiente del quehacer de una organización en el logro de sus objetivos institucionales. Existen antecedentes previos de su utilización en el campo de los estudios migratorios como puede observarse en la contribución de Thayer y Durán (2015).
} 
de origen, tendencias de inserción laboral, entre otros. En cuarto lugar, se arrojan los resultados del trabajo de campo sobre la identificación de nudos críticos en la inserción de la población migrante de origen regional, en los ámbitos de la salud y la educación, y el ejercicio de la ciudadanía sustantiva. Finalmente, se presentan las conclusiones.

\section{La inserción social de la población migrante y el acceso efectivo a derechos desde la óptica local}

Según un informe reciente del Instituto de Políticas Públicas de Derechos Humanos del Mercosur, los desafíos en torno a la inclusión social de los migrantes y la implementación de acciones orientadas a garantizar sus derechos en distintos ámbitos de los países de recepción, obligan a redirigir cada vez más el análisis hacia las ciudades, los municipios y las áreas metropolitanas (Organización Internacional para las Migraciones [oIM], Instituto de Políticas Públicas en Derechos Humanos del Mercosur [IPPDH], 2017).

Desde esta óptica, se interpreta que el vínculo entre migraciones y ciudades denota gran importancia en la actualidad para el diseño y la implementación de políticas migratorias desde el enfoque de los derechos humanos. Las ciudades constituyen un espacio privilegiado para el estudio de las dinámicas y los resultados de las diversas formas de inserción social, focalizando en las modalidades en que los migrantes trabajan, viven, configuran hábitats locales y acceden $-\mathrm{o}$ no- a sus derechos en los entornos urbanos. En este sentido, se reconoce que los espacios locales se encuentran en el corazón de las complejas relaciones entre la globalización, los procesos de integración regional y las políticas públicas (OIM, IPPDH, 2017).

Camós (2017) enfatiza que si bien es cierto que los movimientos migratorios internacionales poseen una dimensión global, es en el ámbito local donde se delimita, por un lado, el proyecto migratorio de una persona o una familia, dado que esta inicia su viaje partiendo de una localidad concreta para llegar a otra, también localizada en un punto exacto del mapa; y por otro, donde se materializa el "hecho migratorio" en sí mismo, ya que tanto la ciudad que emite como la que acoge a los migrantes internacionales, experimenta una significativa transformación, adoptando diferentes formas, intensidades y caracteres.

Este impacto local en la ciudad receptora va a variar de acuerdo al número de migrantes que arriban o el stock acumulado; su proporción sobre la población total residente; la procedencia de los flujos; el carácter temporal, circular o permanente de los proyectos migratorios; la tradición receptora de la ciudad; los segmentos locales del mercado de trabajo donde ingresan; la convivencia en los barrios, escuelas, hospitales, salitas; y las expresiones culturales que transforman las prácticas y hábitos de la comunidad (Garcés, 2014; Stefoni, 2009, 2011; Thayer y Durán, 2015).

Adicionalmente, en el ámbito local se encuentra el municipio que es la administración más próxima a la ciudadanía, y, aunque generalmente no dispone de los resortes normativos, las competencias suficientes y los recursos necesarios, se encuentra ante la necesidad de resolver demandas planteadas por la población migrante en distintos espacios de inserción social. Aquí, la importancia del Estado local tiene un doble sentido: primero, como agente directo en la gestión del reconocimiento de los migrantes como sujetos de derecho, y segundo, como actor que transfiere hacia 
los niveles superiores del Estado los elementos del conflicto en la incorporación de los migrantes a la comunidad receptora (Belil, 2017; Camós, 2017; Thayer y Durán, 2015). Por todo lo expuesto, se asume que el problema del reconocimiento efectivo de derechos se juega, en gran medida, en los espacios locales.

Ahora bien, la identificación de nudos críticos en el acceso de los migrantes regionales a la educación y la salud pública en Bahía Blanca, ubica este trabajo en los análisis y discusiones en torno a la ciudanía formal y la ciudadanía sustantiva, y a los elementos emergentes del necesario ajuste entre ambas dimensiones.

Vale mencionar que existen profusos antecedentes respecto del abordaje del vínculo migraciones-ciudadanía. Sin ánimos de exhaustividad, pueden citarse los aportes de Pereyra (2005), Suárez-Navaz (2005), Domenech (2008), Mezzadra y Nielson, (2014), entre otros; así como aquellos que se ocupan de analizar el acceso de la población migrante a la atención en salud y la educación (Liberona y Mansilla, 2017; Fuks et al., 2008; Goldberg, 2014; Jelín, 2007), algunos de los cuales se retoman más adelante.

En este texto no se apela a una definición estática y convencional de la ciudadanía, que entiende a la población migrante como componente excluido de la misma, y que concibe al "extranjero" como objeto de una condición legal de no pertenencia a una comunidad. Por el contrario, se entiende la ciudadanía como un proceso de construcción del sujeto de derechos, que involucra a todos aquellos que participan de un modo u otro en una nación, involucrando distintos agentes de construcción (Pereyra, 2005). Siguiendo a esta autora, se avanza en la interpretación de que:

Los aspectos formales de la ciudadanía no son suficientes para asegurar la equidad de hecho y el igual acceso a derechos sociales... no garantizan el acceso igualitario al bienestar social, a la participación política activa y a la libertad. La ciudadanía substancial se refiere a la igualdad de hecho y al acceso equitativo de los bienes sociales, a que cada individuo de una comunidad socio-política sea sujeto de derechos (Pereyra, 2005, p. 62).

El proceso de construcción de ciudadanía substancial implica la intervención de diferentes agentes y niveles de acción. Por una parte, la definición de normativas y políticas que permiten la inclusión y exclusión de los migrantes a ciertos derechos y beneficios sociales. Estas normativas, tienen como principal protagonista al Estado, aunque suelen reflejar ideas socialmente construidas sobre el lugar que ocupan los inmigrantes en el proyecto de país (Mármora, 2002). La política migratoria —así como todo el marco legal que define los derechos de los migrantes en las distintas áreas de participación social一, constituye un elemento central para asegurar una ciudadanía plena, pues muchas organizaciones centran sus energías en estas modificaciones, y además generan un marco de referencia desde el cual es posible hacer reclamos cuando estos no se cumplen — criterios de exigibilidad- (Pereyra, 2005).

Pero no es un nivel de análisis suficiente, pues, como advierte Mármora (2002), pueden existir marcos normativos de avanzada en términos de reconocimiento de derechos ya sea sociales, políticos o civiles, que coexisten con excesos de la fuerza pública al momento de su aplicación; que pueden vincularse a prácticas administrativas poco transparentes por parte de los agentes estatales hasta las más extremas manifestaciones de discriminación "por portación de rostro". Es decir, existen mecanismos formales e informales que facilitan u obstaculizan el acceso de los migrantes a los bienes sociales; y las instituciones estatales juegan un papel importante legitimando o no esos derechos, aplicando o ignorando ciertas normas (Pereyra, 2005). 
Al mismo tiempo, la lucha por el ejercicio de derechos por parte de los migrantes, implica también la concepción de sí mismos como sujetos de derecho. Como señalara Habermas (1998), una distribución igualitaria de derechos resulta posible solo cuando quienes gozan de derechos se reconocen mutuamente como libres e iguales. Es por ello que la desnaturalización de ciertas relaciones desiguales basadas en la nacionalidad constituye un prerrequisito esencial para cualquier lucha por derechos ciudadanos.

\section{Estado, política y legislación migratoria: Los derechos sociales de la población migrante}

Las políticas migratorias constituyen el conjunto de normas, leyes e instrumentos estatales destinados a regular el acceso secuencial de los migrantes a diferentes esferas de la sociedad de acogida y como prolongación natural, el acceso gradual a la titularidad de derechos (López, 2005). Cuentan con tres dimensiones fundamentales: la denominada esfera del control y regulación, que determina las condiciones de ingreso y permanencia de los migrantes al territorio nacional; la esfera de la integración, que atiende a las estrategias de incorporación socioeconómica y cultural a la sociedad receptora (incluyendo su acceso a derechos sociales); y la esfera de la nacionalidad, que determina las formas de incorporación de los inmigrantes a la comunidad política del país receptor (Arango, 2000; López, 2005). Si bien este artículo se ocupa de la segunda esfera mencionada, se parte de asumir que la primera la afecta y atraviesa indefectiblemente (CEIPIL, 2011).

En Argentina, la política migratoria se encuentra explícitamente contenida en normas constitucionales, leyes, decretos y resoluciones, tratados internacionales y regionales, entre otros dispositivos. Este país es parte de los instrumentos internacionales más importantes que conforman el sistema universal e interamericano de derechos humanos, gran parte de los cuales gozan de jerarquía constitucional. También ha ratificado la Convención Internacional sobre la Protección de los Derechos de todos los Trabajadores Migratorios y sus Familiares, y en el ámbito del Mercosur, fue el primero en ratificar el acuerdo de residencia entre Estados parte y asociados que, además de la simplificación de procesos de acceso a la residencia entre los países del bloque, determinó el reconocimiento de la igualdad de derechos civiles y libertades sociales, culturales y económicas entre los nativos y los migrantes que hayan obtenido la residencia en el país de recepción.

Este acuerdo establece que será aplicado sin perjuicio de normas o disposiciones internas de cada Estado parte "que sean más favorables a los inmigrantes" y es por ello que seguidamente se coloca especial énfasis en la normativa migratoria vigente.

La sanción de la Ley de Migraciones No 25.871 (2004), de referencia en la región sudamericana, tuvo como origen una amplia y extensa lucha de distintas organizaciones sociales que reclamaban la derogación de una norma dictada por el último gobierno de facto (1976-1983), violatoria de los derechos humanos de los migrantes (Badaró, 2006; Correa, 2004; Nicolao, 2014 y otros). Esta norma parte de reconocer a la migración como un derecho fundamental e inalienable de la persona, que se debe garantizar sobre la base de la igualdad de trato (Centro de Estudios Legales y Sociales (CELS), Federación Internacional de Derechos Humanos (FIDH), 2011) y avanza en el reconocimiento formal de un amplio catálogo de garantías que a continuación se especifican. 
En el ámbito del control y la regulación, innova en la incorporación de la categoría de "residencia temporaria por nacionalidad" (Ley No 25.871, 2004, art. 23, inciso 1), según la cual los migrantes originarios de países miembros y asociados del Mercosur, tienen derecho a una residencia por dos años, prorrogables con entradas y salidas múltiples, por el solo hechos de ser ciudadanos de países con los cuales Argentina comparte un proyecto de integración regional.

Esto tiene un impacto directo en la población bajo estudio, ya que a diferencia de los trabajadores migrantes de otras procedencias, están exceptuados de acreditar contratos laborales que indiquen relación de dependencia.

En segundo lugar, la ley consagra en su art. 9, el derecho de los migrantes y sus familias "a recibir información" (y la obligación del Estado a proporcionarla), sobre sus derechos y obligaciones en la sociedad receptora (a); los requisitos para su admisión, permanencia y egreso del país (b); y todos aquellos temas que le permitan cumplir formalidades administrativas o de otra índole en Argentina (c). Además, la autoridad de aplicación de la ley, la Dirección Nacional de Migraciones (DNM), debe adoptar todas las medidas que considere apropiadas para difundir la información mencionada y ocuparse de que esta sea suministrada por empleadores, sindicatos u otros órganos $\mathrm{o}$ instituciones de manera gratuita y, en la medida de lo posible, en un idioma que puedan entender (Ley No 25.871, 2004).

Este aspecto se revela como esencial para al logro de una efectiva igualdad de trato, ya que la falta de información, a veces agravada por la barrera idiomática, se convierte comúnmente en un obstáculo para el ejercicio práctico de derechos sociales.

En la esfera de la integración, existen tres artículos de la ley que resultan centrales para comprender la cobertura de derechos sociales de los migrantes. El artículo 6 establece que:

El Estado en todas sus jurisdicciones, asegurará el acceso igualitario a los inmigrantes y sus familias en las mismas condiciones de protección, amparo y derechos de los que gozan los nacionales, en particular lo referido a servicios sociales, bienes públicos, salud, educación, justicia, trabajo, empleo y seguridad social (Ley No 25.871, 2004).

En el ámbito específico de la educación, el artículo 7, dispone: "En ningún caso la irregularidad migratoria de un extranjero impedirá su admisión como alumno en un establecimiento educativo, ya sea este público o privado; nacional, provincial o municipal; primario, secundario, terciario o universitario" (Ley No 25.871, 2004, art. 7).

Con el mismo sentido, según el artículo 8 "No podrá negársele o restringírsele en ningún caso, el acceso al derecho a la salud, la asistencia social o atención sanitaria a todos los extranjeros que lo requieran, cualquiera sea su situación migratoria" ${ }^{5}$ (Ley $\left.\mathrm{N}^{\mathrm{o}} 25.871,2004\right)$.

Además, las autoridades de los establecimientos educativos y sanitarios tienen la obligación de brindar orientación y asesoramiento a los efectos de subsanar la irregularidad migratoria de los migrantes que tomen contacto con cada institución (arts. 7 y 8 ).

\footnotetext{
${ }^{5}$ El reglamento agrega que la identidad de los migrantes podrá ser demostrada mediante la documentación extendida por las autoridades de su país de origen o consulados en el país (Ley $N^{\circ} 25.871,2004$, art. 8).
} 
Existe otro conjunto de disposiciones que los complementan, como el art. 13 que define como discriminatorios todos los actos u omisiones por motivos de etnia, nacionalidad (entre otros), que arbitrariamente impidan, obstruyan o restrinjan el pleno ejercicio sobre bases igualitarias de los derechos y garantías fundamentales reconocidas. Y el artículo 14, que responsabiliza al Estado "en todas sus jurisdicciones" (nacional, provincial, municipal), en el desarrollo de iniciativas tendientes a la "integración de los extranjeros" en su comunidad de residencia, incluyendo a) la realización de cursos de idioma castellano en las escuelas; $b$ ) la difusión de información útil para la adecuada inserción de los extranjeros en la sociedad argentina; $c$ ) el conocimiento y valoración de sus expresiones culturales, recreativas, sociales, económicas y religiosas y d) la organización de cursos de formación, inspirados en criterios de convivencia en una sociedad multicultural y de prevención de comportamientos discriminatorios para funcionarios y empleados públicos.

Si se reflexiona sobre los contextos locales, se evidencia que estos artículos reconocen la necesaria participación de los distintos niveles del Estado, pero queda en una esfera de "vaguedad" la distribución de responsabilidades y las competencias que detentan los municipios en este esquema. Desde el punto de vista operativo, el reglamento de esta norma (Decreto $\mathrm{N}^{\circ} 616,2010$ ), no resuelve dicha limitación: establece la obligación del Estado nacional, a través de la DNM, de trabajar "en colaboración " con otras áreas del gobierno (caso de los arts. 6, 7, 8 y 14), pero no se precisa ningún tipo de modalidad o instrumento para materializar la articulación exigida.

Con todo, el país cuenta con una política migratoria que ofrece un marco garantista en materia de derechos sociales para las personas migrantes el cual debe contrastarse con el funcionamiento de la institucionalidad actuante en distintas esferas.

Ahora bien, no puede dejar de mencionarse que, en los últimos años, en el marco del gobierno nacional argentino encabezado por el presidente Ing. Mauricio Macri, se impulsó una reforma normativa, que si bien no afecta directamente el articulado de la Ley $\mathrm{N}^{\circ} 25.871$ en materia de derechos a la educación y la salud de la población migrante, sí trastoca otras esferas de actuación, dando paso a una regresividad en el marco regulatorio con enfoque de derechos previamente citado.

Por ejemplo, a través de un Decreto de Necesidad y Urgencia (DNU) $\mathrm{N}^{\circ} 70$ (2017), el Poder Ejecutivo materializó una reforma, discursivamente fundada en la asociación migración-delito e inseguridad ciudadana que dispone, entre otras cosas, la ampliación de las causas de denegación y cancelación de residencia en el país, así como las de expulsión; debilita el derecho de defensa, y extiende o acelera las posibilidades de detención de migrantes sujetos a un trámite de expulsión (Caggiano, 2017). ${ }^{6}$

En la construcción discursiva del migrante como "delincuente", "peligroso", o "responsable de alterar la paz social", se viene abonando un escenario en el cual se fomentan prácticas de discriminación, xenofobia y precarización laboral. Tanto el presidente de la nación, como altos funcionarios del gobierno nacional y de provincias argentinas receptoras de inmigración regional, han expresado públicamente la necesidad de reformular la normativa migratoria vigente, con vistas a su endurecimiento. Según sus declaraciones, se busca restringir derechos básicos como el de la salud y la educación (o someterlos a un criterio de reciprocidad con el país de origen de los migrantes), y han elaborado proyectos de reforma en esta dirección.

${ }^{6}$ Este decreto fue declarado inconstitucional, el gobierno nacional apeló a la misma, y hasta la decisión de la Corte Suprema de Justicia, la medida sigue vigente. 
En consecuencia, este contexto de progresivo cuestionamiento al corpus de garantías que establece la Ley $\mathrm{N}^{\circ} 25.871$, no puede dejar de tenerse en cuenta al momento de evaluar el ejercicio efectivo de derechos sociales por parte la población migrante, en tanto influye directa e indirectamente en su legitimación como sujetos de derechos.

Como complemento de lo anteriormente expuesto, a continuación, se describe sucintamente el escenario local y las características de la población migrante bajo estudio.

\section{Bahía Blanca: Contexto y perfil migratorio}

La provincia de Buenos Aires ha constituido el destino más atractivo para los migrantes internacionales que arribaron histórica y contemporáneamente a la Argentina y actualmente acoge a 52\% de toda la población migrante del país (Instituto Nacional de Estadísticas y Censos [INDEC], 2010). Dentro de la región conocida como "Interior Bonaerense", en el sudoeste de la provincia, se emplaza el municipio de Bahía Blanca, conformado por la ciudad homónima, cabecera del municipio, y las localidades de Ingeniero White, General Daniel Cerri y Cabildo.

Es el tercer partido más importante de esta región por su tamaño demográfico, con una población que asciende a 301572 personas. Receptor histórico de corrientes migratorias internacionales, la población migrante alcanza según el último censo a 13 502 personas, lo que representa $4.5 \%$ del total de habitantes, provenientes en $79 \%$ de países sudamericanos (INDEC, 2010) (Figura 1).

Figura 1: Distribución de la población migrante por regiones de origen en el municipio de Bahía Blanca, 2010

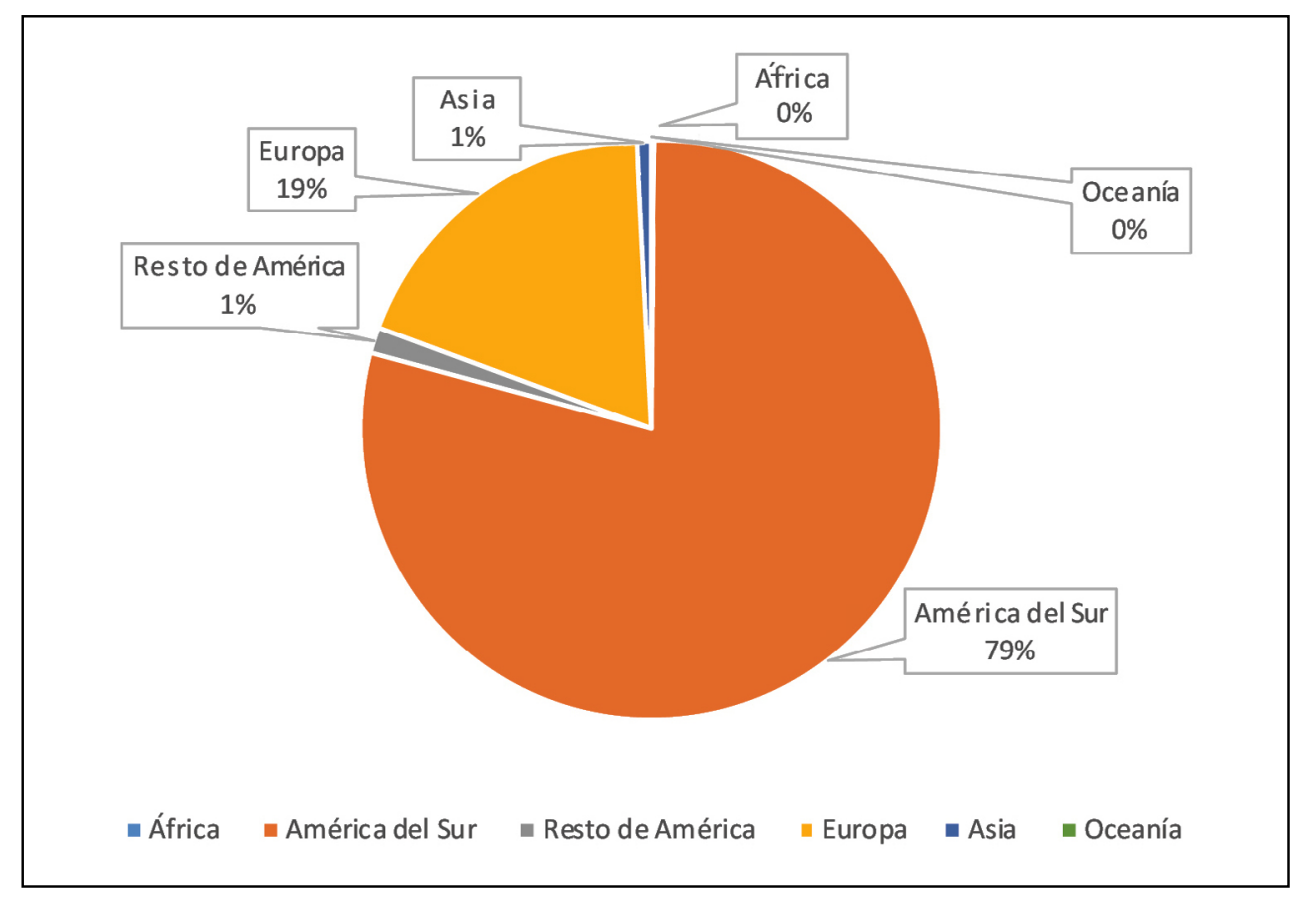

Fuente: Elaboración propia con base en INDEC (2010). 
La comunidad chilena es la de mayor peso numérico del conjunto, equivalente a $83 \%$ del grupo regional, y $65 \%$ del total (INDEC, 2010) (Figura 2).

Figura 2: Distribución de la población migrante del Mercosur por país de nacimiento en el municipio de Bahía Blanca, 2010

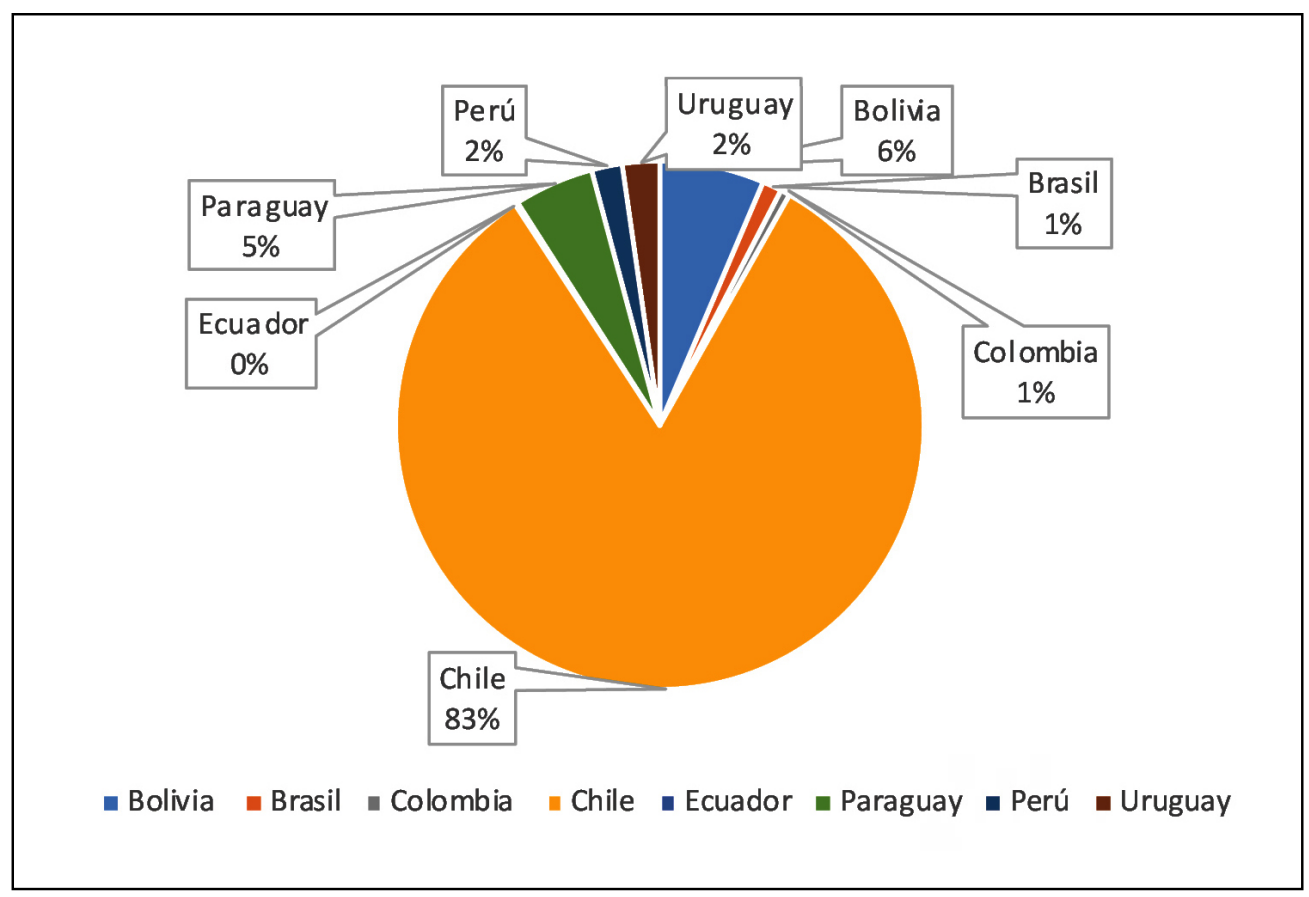

Fuente: elaboración propia en base a INDEC (2010).

La migración regional es una migración eminentemente laboral, constituida por personas que se desplazan para acceder a un empleo, mejores condiciones salariales y mayores posibilidades de ascenso social. En la estructura discursiva de los migrantes, no solo las oportunidades laborales ocupan un lugar central en la decisión migratoria, sino también, el acceso gratuito al sistema de salud pública y al sistema educativo, significando este último una herramienta de ascenso social que funciona como un factor de atracción central de Argentina en el contexto latinoamericano (Nicolao, 2014).

En cuanto a su inserción laboral, lejos de presentarse un panorama homogéneo, existen divergencias según países de origen, tiempo de residencia en el lugar de destino, de género o nivel de instrucción. Sin embargo, como denominador común, sobresale su incorporación en actividades laborales de baja calificación, mayores niveles de informalidad, y percepción de salarios más reducidos que la población nativa (IPPDH, Defensoría del Pueblo de la Provincia de Buenos Aires, 2014).

Con respecto a los grupos más importantes, la migración de agricultores chilenos a Bahía Blanca se remonta a mediados del siglo xx. Tuvo su auge durante la dictadura pinochetista (1973-1990), con un movimiento socialmente diversificado que abandonó su carácter estacional y destino rural, para direccionarse a sectores urbanos. Actualmente, estos grupos se ocupan en el ámbito de los servicios (vendedores en supermercados, tiendas), de la construcción (como albañiles de 
distinto nivel de calificación) y en el sector agrícola. Estos movimientos presentan bajos niveles de renovación, resultando una población envejecida que incluye movimientos de retorno (INDEC, 2010; Instituto Nacional de Estadísticas [INE], Ministerio de Relaciones Exteriores [Minrel-Dicoex], 2017; Torrecilla, 2014).

La migración boliviana comenzó en los años setenta a arribar a la zona hortícola del valle bonaerense del Río Colorado para luego trasladarse a Bahía Blanca, en el marco de un fenómeno que se ha expandido contemporáneamente en los cinturones verdes de distintos centros urbanos del país, denominado "bolivianización de la horticultura". Se define por la participación protagónica de familias bolivianas en la producción de hortalizas para su consumo en fresco, en explotaciones donde pueden escalar de asalariados, a medieros y a pequeños propietarios. La localidad de Daniel Cerri concentra gran parte de estos grupos en el denominado "sector quintas". Hoy, la migración boliviana constituye el flujo con más alto nivel de ingresos, con destino rural y urbano; en este último caso, con inserción en el sector de la construcción albañiles, ceramistas, yeseros- (Benencia, 2012; Ciarallo, 2007; Kraser y Ockier, 2007; Toranzos, 2014; Torrecilla, 2014).

La población paraguaya representa un grupo que supera las 500 personas, con una inserción similar a la boliviana: en quintas (zona rural) y en la construcción (zona urbana). El movimiento peruano tuvo su auge en el decenio de 1990, y evidencia débil dinamismo en la actualidad. Se caracteriza por su inserción urbana, población con mayores niveles relativos de instrucción y mayoría femenina (INDEC, 2010).

El venezolano, en cambio, parece emerger como un grupo más diferenciado del conjunto, de desarrollo reciente y en pleno crecimiento, asociado a la crisis económica, política y social que atraviesa este país sudamericano. Según el testimonio de una de las migrantes pioneras de este origen, esta corriente migratoria tiene aproximadamente cuatro años de desarrollo en Bahía Blanca, y una población estimada que superaría las 300 personas (Claudia, referente de la comunidad venezolana, comunicación personal, 24 de marzo de 2018).

Como tendencia general, las mujeres migrantes de origen regional se incorporan en el servicio doméstico, en el sistema de cuidados en sentido amplio y también se dedican a la comercialización de diversos productos en la ciudad —alimentos, indumentaria, calzado- (Toranzos, 2014).

Las características citadas proporcionan un marco para contextualizar y favorecer la interpretación de los resultados de investigación.

\section{Nudos críticos en el acceso a derechos sociales en el ámbito de la salud y la educación: Actores e instituciones en la construcción de la ciudadanía sustantiva}

En esta sección se reportan los resultados del análisis sobre las condiciones de acceso real de la población migrante regional a los derechos sociales en el ámbito de la salud y la educación en Bahía Blanca, en virtud de lo que la normativa migratoria vigente dispone en los artículos citados en el apartado previo (6, 7, 8, 13 y 14).

Ante el reducido número de investigaciones previas sobre la temática, se reconstruyen los focos de conflicto más sobresalientes (nudos críticos), tomando en cuenta la voz de los sujetos migrantes y la de aquellos actores que median o intervienen 
directa o indirectamente, formal e informalmente, en la institucionalidad de estos ámbitos. ${ }^{7}$

En Bahía Blanca, como en cualquier otro contexto receptor, las instituciones públicas y sociales juegan un papel importante en las posibilidades o constreñimientos que atraviesan los migrantes en su incorporación a la vida en la comunidad local. Por eso, además del complejo institucional que conforma el sistema de salud pública o el sistema educativo, se debe considerar la presencia de una delegación de la DNM, localizada en la ciudad cabecera como consecuencia del peso cuantitativo de la población migrante en su zona de jurisdicción ${ }^{8}$ el emplazamiento de consulados de diversos países en la ciudad (Brasil y Chile, entre los sudamericanos); el amplio conjunto de organizaciones de migrantes que funciona en el territorio (más de 50 entre europeas y latinoamericanas); o la Pastoral Migratoria que funciona hace 35 años en el distrito, brindando asistencia social a la población migrante.

Se confirma que los migrantes interactúan con ellas en distinto grado de intensidad mientras sus trayectorias migratorias se configuran en etapas en las que las expectativas y necesidades de los sujetos son distintas y, al mismo tiempo, la relación con el entorno, tanto institucional como social, también lo es.

(1) Uno de los primeros nudos críticos que revela el trabajo de campo como elemento transversal a las áreas analizadas, gira en torno a las dificultades derivadas para el acceso a la residencia de los migrantes de reciente arribo. Más allá del tratamiento favorable que la Ley $\mathrm{N}^{\circ} 25.871$ definió para los ciudadanos del Mercosur, así como la existencia de una delegación de la DNM en territorio bahiense, las gestiones para acceder a la misma siguen representando una de las primeras problemáticas con las que se encuentran los migrantes en su primera acogida.

Este no constituye un dato menor ya que, como se observará en adelante, los problemas "de papeles" atraviesan, condicionan y limitan las posibilidades del ejercicio sustantivo de derechos en otras esferas sociales, incluso a pesar de que estos deban garantizarse independientemente de la condición administrativa de los migrantes.

Se revelan como dificultades centrales la obtención de los certificados de Carencia de Antecedentes Penales, que solo se otorgan en reparticiones oficiales en los países de origen o en Argentina, a través de los consulados; y los sellos de ingreso al país para aquellos que arriban por pasos no oficiales, o que incluso haciéndolo, los extravían.

Asimismo, existe coincidencia entre los migrantes en que no reciben información ni asesoramiento estatal en este proceso. Aunque la DNM tenga a su cargo esta responsabilidad específica (según el art. 9), no se incluye como política del organismo que se desarrolle pro-activamente en el territorio. Así, el acompañamiento en los trámites, atraviesa esquemas de articulación que se gestan a escala local, en el que se involucran actores que cubren el vacío o ausencia del Estado en el asesoramiento

\footnotetext{
${ }^{7}$ Los fragmentos de entrevistas transcriptos resguardan el anonimato de los informantes migrantes a través de la utilización de nombres ficticios, reproduciendo fielmente los testimonios obtenidos y experiencias orales directas (López y Deslauriers, 2011).

${ }^{8}$ Este organismo se encarga de aplicar normativa migratoria promoviendo la regularización de la situación migratoria de los extranjeros en el territorio de su jurisdicción, con competencia para otorgar residencias, prórrogas, cambios de categorías migratorias y concesión de permisos de ingreso. Existen 29 en todo el país, 6 en la provincia de Buenos Aires, incluida la de Bahía Blanca, con jurisdicción en 26 partidos bonaerenses y 22 de La Pampa.
} 
y proporción de información, e incluso actuando como mediadores-facilitadores de la gestión de certificaciones en instancias previas al acceso a la residencia (Pastoral Migratoria, consulados, organizaciones de migrantes):

Nosotros trabajamos con todo el inmigrante que viene y se acerca. Se tramitan acá, con nuestra administración, certificados de antecedente penales, los mandamos nosotros a la sede nuestra en Buenos Aires y ahí los ayudan en la gestión en las embajadas correspondientes de Perú, Bolivia, Venezuela. Este certificado es fundamental para sacar la residencia precaria que es la primera que tienen que sacar, y es lo más complejo de obtener. Nosotros estamos en comunicación con la DNM. Cuando ellos ven gente que va a preguntar y no se sabe manejar, lo mandan para acá (María, Pastoral Migratoria, comunicación personal, 19 de noviembre de 2017).

La problemática más común es el tema de documentación, porque la mayoría entra ilegalmente o pierde los documentos de Bolivia acá en Argentina, y acá ya tiene que hacer otro tramiterío, así que la demanda más tradicional son papeles. Nosotros en esos casos hacemos de nexo, les decimos qué días tiene que ir a Migraciones, qué tienen que llevar, o las veces que viene el cónsul boliviano de Río Negro, reunimos a la gente que necesita ayuda con el papelerío. Es una demanda constante (Aldo, referente colectividad boliviana, comunicación personal, 28 de mayo de 2018).

En el caso de la población venezolana, de reciente arribo, los testimonios obtenidos refieren que:

Ellos tienen otra realidad, los que venían hace seis meses venían con toda su documentación, el acceso a la residencia lo resolvían de manera más sencilla, ahora vienen como huyendo, es gente de clase media en general, muchos universitarios, que vienen a trabajar de lo que surja, y están acercándose cada vez más por tema de papeles (María, Pastoral migratoria, comunicación personal, 19 de noviembre de 2017).

Como podrá observarse más adelante, estas dificultades repercuten y se trasladan directamente al ámbito de la salud y la educación, generando problemas diversos.

\section{Salud pública y atención sanitaria}

Dentro de las experiencias que remiten al acceso al sistema de salud pública por parte de los migrantes regionales, partiendo de la premisa que el grueso de estas comunidades no cuenta con otro tipo de cobertura médica que no sea la que brinda el Estado (IPPDH, Defensoría del Pueblo de la Provincia de Buenos Aires, 2014), es importante describir brevemente cómo funciona el sistema de salud público local, en correspondencia con el sistema nacional.

Bahía Blanca posee 54 Unidades Sanitarias ("salitas") en todo el territorio, incluyendo las ubicadas en la ciudad cabecera y delegaciones municipales, sumado a un Hospital Municipal de Agudos "Dr. Leónidas Lucero" y un Hospital Interzonal General de Agudos "Dr. José Penna", de gestión provincial, todas instituciones de atención gratuita. 
Las salitas forman parte del sistema de Atención Primaria a la Salud (APS), donde se brinda la asistencia sanitaria y esencial, y se concreta el primer contacto entre la comunidad y los servicios de salud. Cuentan con equipos interdisciplinarios y están emplazadas en los barrios. Por su parte, los centros hospitalarios poseen guardia de 24 horas para emergencias, y servicios de distintas especialidades que cuentan con consultorios externos e internación. Para recibir atención en los mismos, excepto urgencias, se requiere acceder a turnos programados con disponibilidad limitada, aspecto inherente a un sistema sobresaturado.

(2) Entre los principales nudos críticos que se identifican en este ámbito figura el desconocimiento de la población migrante sobre los procedimientos a seguir para la utilización de los servicios y recursos de salud pública en la comunidad local. La falta de información sobre el funcionamiento de la institucionalidad sanitaria en la primera acogida, y sobre los derechos que le son garantizados (condición indispensable para su exigibilidad), es un proceso que lleva tiempo, y que requiere de mediadores — paisanos o instituciones alternativas- que tiendan puentes con el sistema:

Muchos de ellos no saben que tienen derecho a la salud, se enferman y no van al hospital, si no tienen plata piensan que no pueden acudir a la salita. Tuve el caso de un nene que necesitaba hacerse una tomografía urgente y como su madre no tenía dinero en ese momento no la hizo, hasta que obtuvo los recursos necesarios para pagar el estudio. Nosotros sabemos que ellos tienen ese derecho, lo peleamos, pero ellos no siempre están informados (Alicia, trabajadora social de Unidad Sanitaria, comunicación personal, 10 de noviembre de 2017).

En el caso de los migrantes con más tiempo de residencia en el partido, esto no se presenta como una problemática, siendo el caso de una proporción importante de los migrantes chilenos entrevistados:

La fisonomía de la comunidad chilena es la de una comunidad de larga data, la mayoría ha formado familia, tiene hijos y nietos argentinos, entonces tiene una red de protección social más densa y más establecida, y eso hace que no se requiera en gran medida de la asistencia del consulado o de otras instituciones para acceder a distintos espacios en Bahía Blanca. Pero también tenemos casos de personas que están en situación más desfavorable, generalmente son inmigrantes más cercanos a esta fecha, más recientes, y ahí sí se requiere ese acompañamiento, cuando tienen problemas sociales, problemas de salud, enfermedades específicas (Cónsul chileno en Bahía Blanca, comunicación personal, 9 de febrero de 2018).

(3) Otro nudo crítico se relaciona con las limitaciones de accesibilidad derivadas del nivel de complejidad de la atención requerida. A menor complejidad de la atención requerida los migrantes experimentan un nivel más elevado de acceso a las unidades sanitarias (entendida como posibilidad de ser atendidos) - aunque no exento de dificultades-, mientras los mayores problemas aparecen cuando se requiere un nivel de complejidad mayor en la atención (en términos de servicios y recursos), en los centros hospitalarios:

El tema salud acá, con las salas médicas, cada barrio más o menos lo soluciona. Las salitas son municipales, y en la sala médica tanto problema 
no hay. Los temas más graves son cuando se necesitan especialistas en el Hospital Municipal o en el "Penna". En estos casos, en el Municipal cuando hemos tenido problemas tenemos que acudir a los directores, que a veces han cedido a nuestros reclamos e intervenciones, y en otras oportunidades, ante la negativa, nos vemos obligados a realizar recursos de amparo, para que pongan un marcapaso a un boliviano, por ejemplo, para que internen una mujer paraguaya... Somos bastante combativos en ese sentido (Elvira, Pastoral migratoria, comunicación personal, 19 de noviembre de 2017).

En los hospitales, las limitaciones más claras se encuentran en situaciones de tratamientos específicos, cirugías, enfermedades crónicas, o en casos en que se requiere determinados medicamentos o prótesis. Se manifiesta asimismo una diferencia entre el Hospital Municipal y el Hospital Interzonal "Dr. José Penna", reconociendo mayor accesibilidad histórica y contemporánea para los migrantes en el segundo. Esto revela que, en ocasiones, el nivel de acceso para la población migrante termina dependiendo de la decisión personal - y por ende, arbitrariade los gestores a cargo de las instituciones, y no del cumplimiento de la normativa migratoria vigente (Ley $\mathrm{N}^{\circ}$ 25.871, 2004, arts. 6, 8):

Con el Hospital Interzonal Penna no tenemos ningún problema. Tenemos problemas con el Hospital Municipal, con el Director que hay ahora (los migrantes que todavía no tienen la precaria, por más que vayan con una urgencia, no los atienden), pero en el Penna no te hacen ningún problema todos los temas de salud que se derivan allí, ya sea chicas derivadas con epilepsia, problemas psiquiátricos, casos de tuberculosis, lo hemos resuelto bien (María, Pastoral migratoria, comunicación personal, 19 de noviembre de 2017).

Antes de tener un documento [emitido en Argentina] nosotros no podíamos asistirnos en la salud en el Hospital Municipal, en cambio en el Hospital Penna sí. Ahora recientemente nos han dicho que el municipal optó también por atendernos con los documentos precarios, o provisorios, bueno, al menos eso me dijeron a mí (Celeste, peruana, comunicación personal, 24 de octubre de 2017).

(4) Las limitaciones de acceso a servicios médicos en los centros hospitalarios se asocian al cuarto nudo crítico identificado, vinculado a la situación administrativa de la persona migrante que solicita el servicio de salud, que por lo general, se materializa mediante trabas burocráticas y administrativas (especialmente ligadas al requerimiento del Documento Nacional de Identificación [DNI] argentino para casos de intervenciones programadas, internación, tratamiento de enfermedades crónicas), que vulneran el artículo 8 de la Ley $\mathrm{N}^{\circ} 25.871$.

(5) El quinto nudo crítico detectado se relaciona a los discursos o prácticas discriminatorias por parte de profesionales de la salud, o de sus pares nativos en contextos de atención médica, basados en percepciones fuertemente arraigadas en el imaginario social argentino, desde las cuales se visualiza a los migrantes como abusadores de los servicios sociales y de salud pública, que se agrava en contextos de crisis, escasez de recursos y sistemas sobresaturados: 
Una vez fui a la salita y una mujer me dijo "lo mejor que podes hacer es volverte a tu país porque ustedes no tienen ayuda de su embajada, de nada... y siempre vienen a pedir ayuda en la salita y después ustedes se van y avisan que tienen mucha ayuda acá y se nos llena Bahía Blanca de bolivianos”... (Rubén, boliviano, comunicación personal, 22 de noviembre de 2017).

(...) en el ámbito de la salud, existe mucha discriminación y eso a veces es una barrera para que la población se acerque, se atienda... En las salitas las mujeres bolivianas suelen sufrir discriminación cuando llevan sus hijos al pediatra, ya que a veces se trata de madres con seis hijos o más, y obviamente piden seis turnos para atenderlos a todos, y la gente se queja e insulta... (Enfermera, Unidad Sanitaria, comunicación personal, 6 de enero de 2018).

Este tipo de discursos y prácticas afectan directa o indirectamente la garantía de derechos en el ámbito sanitario y suelen provocar un alejamiento de la población migrante del sistema, además de la vulneración de sus derechos en el ámbito sanitario. En este marco, el grupo de origen boliviano emerge como el "otro" más diferenciado con características propias (lenguaje, vestimenta, costumbres) y rasgos fenotípicos diferenciados (Jelín, 2007) que lo convierten en el grupo más vulnerable.

Asimismo, el discurso que liga migraciones y delito en la Argentina de los últimos años, y el progresivo cuestionamiento del acceso de los migrantes a derechos sociales básicos como la salud y la educación, también es percibido por algunos actores sociales como una situación de alarma, por su potencial impacto en el recrudecimiento de prácticas discriminatorias y xenófobas:

Es un discurso que comienza a repetirse cada vez más, ahora con todo esto que salió en los medios con el acceso de los migrantes a la salud pública, es como que se reactualizó. Yo hablé en esa oportunidad con el Secretario de la Fundación Comisión Católica Argentina, el obispo de Azul, para poder elaborar algún documento, con las propuestas nuestras, en base a la ley migratoria (María, Pastoral Migratoria, comunicación personal, 19 de noviembre de 2017).

(6) El sexto nudo crítico registrado se relaciona con las situaciones interculturales que se producen en el contexto de hospitales, salitas, y en general en las consultas médicas. Este tema también afecta y atraviesa a los migrantes y a la calidad de la atención médica que reciben. Sobresalen testimonios de dificultades comunicativas, diferentes conductas o prácticas que inciden en las situaciones de atención (en el caso de las mujeres, en sus formas de dar a luz o practicar la lactancia, p.e.), disímiles pautas de alimentación, de higiene, de vestimenta, en las que se testimonia distanciamiento, falta voluntad en la comprensión y respeto de la diversidad cultural, e incluso experiencias de rechazo por parte de los profesionales de la salud.

Con todo, no puede soslayarse que, desde la mirada del sujeto migrante, que no se desprende de la lógica comparativa entre el lugar de origen y destino, de ese "yo escindido" en tanto sujetos "partidos" temporal y especialmente entre el "allí" y el "acá", entre el antes y el después de la experiencia migratoria (Varela, 2005), se percibe una valoración de la salud pública en el contexto receptor que sigue siendo altamente positiva. 


\section{Los desafíos de inserción en el ámbito educativo}

En el plano de la educación pública, si bien es imposible hablar de la inserción educativa de los migrantes abarcando este proceso en su total magnitud y complejidad, existen algunos elementos recurrentes que emergen de testimonios de población migrante y trabajadores del sistema educativo primario y secundario, que es importante contrastarlos con lo que define la legislación migratoria en sus artículos 6, 7, 13 y 14.

La educación en Argentina en instituciones del Estado es gratuita en los niveles inicial, primario, secundario y terciario, así como en las carreras de grado de nivel universitario. Desde 2014, la obligatoriedad escolar se extiende desde los cuatro años de edad hasta la finalización del nivel secundario. En la provincia de Buenos Aires, la Ley de Educación Provincial No 13.688 (2007) establece en su art. $5^{\circ}$ que el Estado debe proveer y garantizar una educación integral, inclusiva, permanente y de calidad para todos sus habitantes, garantizando la igualdad, gratuidad y justicia social en el ejercicio de este derecho.

Por su parte, se concibe a la educación intercultural como la modalidad responsable de impulsar una perspectiva pedagógica intercultural en articulación con la educación común, complementándola y enriqueciéndola, e incluyendo entre sus funciones: asegurar el derecho de "las comunidades migrantes a recibir una educación intercultural y/o bilingüe que ayude a preservar, fortalecer y recrear sus pautas culturales, sus lenguas, sus cosmovisiones, sus tradiciones e identidades étnicas" (Ley No 13.688, cap. xIII, art. 44, inciso f).

El trabajo de campo permite detectar nudos críticos que se relacionan con el ingreso, permanencia e incorporación de estudiantes migrantes al sistema educativo en Bahía Blanca.

(7) Siguiendo la enumeración general, el séptimo elemento identificado, en coincidencia con lo que sucede en el ámbito de salud, se asocia a las limitaciones que trae aparejada la condición migratoria irregular o carencia de DNI de las personas migrantes. Si bien no se registran casos en que se impida la inscripción de migrantes en situación de irregularidad, se detectan otro tipo de inconvenientes que obstaculizan o demoran burocráticamente este proceso; entre ellos, la ausencia de mecanismos o directivas claras acerca de la certificación de estudios previos en sus países de origen y sus equivalencias con el sistema argentino y la regularización de su situación administrativa para la obtención del título una vez egresados:

El ingreso a la escuela de mi hija la menor fue complicado al inicio porque no traía los documentos del primario de allá, fue un error grande, bueno eso me costó un montón de dinero... Y encima repitió un año acá porque tenía que empezar un año atrás para empezar el secundario. Acá tuvo que hacer de nuevo sexto (Ana, peruana, comunicación personal, 13 de marzo de 2018).

El mayor problema es de tipo burocrático, en relación a la certificación sobre el nivel de estudios alcanzado en su país y su equivalencia acá. El proceso que debe seguirse es largo hasta que se determine el año en que debe ingresar, y mientras tanto el potencial alumno no está escolarizado (directora de escuela primaria, comunicación personal, 11 de febrero de 2018). 
Asociado a ello, se reconoce un desconocimiento relativamente generalizado sobre la ley migratoria por parte de los trabajadores de la educación, y eso redunda en falta de legitimidad de la población migrante como sujeto de derechos, así como incumplimiento de la obligación que tienen las instituciones escolares de brindar acompañamiento en los trámites a las familias que así lo requieren (Ley No. 25.871, 2004, art. 7). En ciertos casos, esta tarea recae en voluntades aisladas que se ocupan de acompañar a las familias, pero con escasas herramientas institucionales; por lo tanto, generalmente, las familias migrantes se encuentran solas en este proceso:

(...) la Directora nos dijo que teníamos que hacer los trámites de la residencia pero nunca nos explicaron más que eso... cómo no teníamos el dinero, y tampoco sabíamos cómo hacerlo, lo fuimos postergando... y perdimos un montón de tiempo para que Pedro entre la Escuela (Teresa, chilena, comunicación personal, 11 de noviembre de 2017).

(8) El siguiente nudo crítico, con un amplio registro de testimonios coincidentes, se vincula a un problema que trasciende la condición migratoria o situación administrativa de los estudiantes, y se asocia a problemáticas sociales más amplias como el trabajo infantil, que causaría la no escolarización de niño/as de comunidades migrantes: "hay un número importante de habitantes de países limítrofes que no están escolarizados. Lo he observado y registrado con intervenciones profesionales en obras de construcción, hornos de ladrillo, y en las quintas, donde los niños están trabajando" (orientadora social, escuela secundaria, comunicación personal, 5 de marzo de 2018).

Este tipo de problemáticas, asociadas a la incorporación de niño/as al sistema de trabajo familiar, también contribuyen a la deserción escolar. Un estudio de Kraser y Ockier (2007) evidencia que en la localidad de Daniel Cerri, el contingente boliviano trabaja en el circuito productivo hortícola en el cual los niños son un componente más de la mano de obra familiar; y cuando su presencia es requerida para las labores agrícolas, los padres dejan de enviarlos a la escuela, con consecuencias negativas en su trayectoria educativa.

(9) En otro orden de problemas e identificado como uno de los nudos críticos más complejos, se advierte la ausencia de herramientas y estrategias de abordaje de la interculturalidad y de prevención de comportamientos discriminatorias en el ámbito escolar (Thayer y Durán, 2015) que permitan allanar distintas dificultades que se presentan en su inserción en el sistema educativo.

A saber, desde la perspectiva de distintos miembros de la comunidad educativa (docentes, directivos, miembros de Equipos de Orientación Escolar, ${ }^{9}$ familias migrantes), los desafíos que atraviesa esta población se pueden agrupar en cuatro conjuntos de problemas: $a$ ) de integración con sus pares, $b$ ) de aprendizaje, $c$ ) de comunicación y $d$ ) de discriminación por su condición de migrantes $\mathrm{y} / \mathrm{u}$ origen nacional o étnico. Estos ejes se afectan e influencian mutuamente, y en algunos casos, no se restringen al ámbito educativo, pues responden a situaciones complejas que involucran aspectos sociales de diversa escala o magnitud.

\footnotetext{
${ }^{9}$ LOS EOE funcionan en los establecimientos educativos e intervienen sobre problemáticas sociales, institucionales y pedagógico-didácticas que involucren alumnos de todos los niveles y modalidades del sistema educativo provincial. Están integrados por orientador educacional, orientador social, maestro recuperador, orientador fonoaudiológico y orientador médico.
} 
Por el lado de las dificultades de integración $(a)$, los educadores argumentan que: "las distancias se ven en las relaciones interpersonales entre pares, a raíz de motes, descalificaciones, aislamiento y autoaislamiento, grupos cerrados, expresiones con contenido discriminatorio y a veces violencia entre pares" (docente de escuela secundaria, comunicación personal, 9 de diciembre de 2017).

En este sentido, se testimonian prácticas de exclusión de alumno/as migrantes al momento de la conformación de grupos para realizar tareas áulicas o en espacios lúdicos, discursos discriminatorios, y situaciones de violencia física.

Los problemas de aprendizaje $(b)$ se presentan asociados a factores como ausentismo, disparidad en la formación recibida entre los sistemas educativos de países de origen y destino y a las "barreras idiomáticas" que afectan el proceso de aprendizaje en general, y de la adquisición de la lectoescritura en particular, en el primer ciclo de la educación primaria:

La solicitud de intervención es por problemas de aprendizaje. Se nota el choque cultural que hay, sobre todo con los bolivianos. En el caso de los paraguayos, en sus casas hablan guaraní, en realidad aprenden más rápido nuestro idioma (por la televisión y por otros medios), pero en la adquisición de la lecto-escritura se nota mucho la brecha que hay con el resto de los alumnos (orientadora educacional, escuela primaria, comunicación personal, 12 de noviembre de 2017).

En cuanto a los problemas de comunicación $(c)$, responde a que muchos estudiantes migrantes ingresan solo hablando su lengua materna (quechua o guaraní), y esto se traslada a la comunicación con docentes, con sus pares, y al propio proceso de aprendizaje, a lo que se le suma la falta de comprensión de determinados códigos de comunicación en el ámbito escolar que trascienden lo estrictamente idiomático.

Por su parte, las situaciones de discriminación $(d)$, se manifiestan mayoritariamente desde lo discursivo. "Peruanita volvete a tu país", "bolita", "paragua", "andá vos, boliviano de mierda", son expresiones recurrentes que relatan los trabajadores de la educación y que ejercen los pares nativos en el ámbito escolar.

Nuevamente, estas expresiones están sustentadas en visiones aún muy arraigadas en la sociedad argentina en relación con la población de este origen y se nutren de mitos y prejuicios como "la invasión silenciosa de los migrantes limítrofes", "los extranjeros que le roban el trabajo a los argentinos", "los inmigrantes que saturan los servicios sociales", "los migrantes que vienen a delinquir". Dentro del grupo regional, las situaciones de discriminación afectan mayoritariamente a la población escolar boliviana, y en menor medida, a la población paraguaya y peruana. Se ejerce por parte de sus pares en las aulas, y en algunos casos aislados, está subyacente en los discursos de docentes que no logran adoptar una mirada de la diversidad. A veces, no solo afecta a los estudiantes, sino que se hace extensivo a sus familias.

Ahora bien, este tipo de ideas, fuente de prejuicios y xenofobia, solo puede derribarse desde el propio ámbito educativo, único sistema capaz de concretar un cambio cultural a partir de la formación de nuevas generaciones. Pero para ello se requiere de educadores capacitados en ideas y valores inclusivos, que logren cumplimentar lo que dispone la ley de educación provincial y la ley migratoria, con herramientas de abordaje de la interculturalidad, que trascienda lo meramente enunciativo. 
El conjunto de situaciones descritas, que se influyen y atraviesan unas a otras, requieren de la intervención sistemática de la institucionalidad educativa, responsable de acoger la diferencia cultural, tender puentes y desarrollar estrategias de convivencia que derriben las situaciones discriminatorias que objetan la presencia de migrantes y sus familias tanto en el ámbito educativo como en distintas esferas sociales.

Así, se percibe que no solo el desconocimiento de la legislación migratoria en el ámbito educativo afecta el cumplimiento de lo dispuesto en el artículo 7 y 14 , inciso b; sino que además, el resto de las disposiciones que favorecen la integración de la población migrante a su comunidad de residencia, están lejos de tener aplicabilidad en el contexto local. En ninguno de los casos estudiados se registra la realización de cursos de idioma castellano en las escuelas (art. 14, inciso a); espacios que promuevan la valoración de las expresiones culturales de los inmigrantes (inciso c), o cursos de formación, inspirados en criterios de convivencia en una sociedad multicultural y de prevención de comportamientos discriminatorios (art. 14, inciso d).

No obstante lo hasta aquí expuesto, nuevamente, como sucede en el ámbito de la salud pública, la educación en sus distintos niveles y modalidades, y su carácter gratuito, es altamente valorada por la población migrante, especialmente por aquellos que han recorrido trayectorias de movilidad social ascendente.

\section{A modo de cierre}

En este trabajo se han identificado los principales nudos críticos en la inserción social de los migrantes regionales en Bahía Blanca, poniendo foco en su acceso efectivo a derechos sociales en el ámbito de la salud y la educación, bajo la premisa que los contextos locales proporcionan un escenario propicio para generar información cualitativa que enriquezca estudios macroexplicativos sobre este fenómeno.

El trabajo avanza en el reconocimiento de problemáticas que atraviesan distintos actores, instituciones y niveles de acción como agentes de construcción de una ciudadanía sustantiva para la población migrante, en el que el Estado es el actor protagónico pero no excluyente.

Desde el punto de vista del reconocimiento formal de derechos a través de la producción de normas (ciudadanía nominal), se observa un marco garantista que toma como núcleo duro la Ley $\mathrm{N}^{\circ} 25.871$. El reconocimiento del derecho a la salud y a la educación en todos sus niveles, se define independientemente de la condición migratoria (regular o irregular) del sujeto migrante; sumado a otras garantías centrales que lo atraviesan como la igualdad de trato, el derecho a recibir información; a no ser discriminados por origen nacional o étnico, y las responsabilidades del Estado en el despliegue de estrategias tendientes a lo que la norma define como la "integración" de los migrantes en su comunidad de residencia. No obstante, en los últimos años se asiste a un escenario político de progresivo endurecimiento de la política migratoria, materializada en discursos y proyectos de ley que cuestionan el enfoque de derechos de la legislación vigente.

Además, desde el punto de vista formal, se advierte la falta de responsabilidades específicas que esta norma y su reglamento le adjudican a los municipios en los mecanismos dispuestos para el reconocimiento efectivo, quedando como actores pasivos ante las definiciones del gobierno nacional. 
Los nudos críticos relevados apuntan a la existencia de mecanismos formales e informales que obstaculizan, demoran y problematizan su ejercicio práctico, generando una débil legitimidad de la población migrante como sujetos de derechos, que hacen que la presencia objetada de los migrantes derive en prácticas y actitudes discriminatorias que, de manera manifiesta o latente, se orientan a su exclusión.

Se evidencia que las instituciones sociales juegan un papel importante deslegitimando derechos o ignorando normas. La condición migratoria del migrante sigue representando una barrera para el acceso al sistema de salud (especialmente en centros hospitalarios), así como a una ágil y plena incorporación al sistema educativo. La falta de información sobre los derechos y obligaciones de los migrantes, sobre los trámites de acceso a la residencia, o el funcionamiento de la institucionalidad sanitaria en la primera acogida, provocan alejamiento, exclusión y débiles mecanismos de exigibilidad. Discursos y prácticas discriminatorias individuales o institucionales basadas en mitos y prejuicios sobre el impacto de la migración regional en destino, agravan la situación planteada y, respecto de la diferenciación por nacionalidades se observa que el grupo de origen boliviano emerge como el "otro" más diferenciado con características propias (lenguaje, vestimenta, costumbres) y rasgos fenotípicos diferenciados que lo convierten en el grupo más vulnerable, y en menor medida, la comunidad paraguaya y peruana.

La condición migratoria y el tiempo de residencia en el lugar de destino siguen funcionando como factores de primer orden en el proceso de construcción de una ciudanía sustantiva. Los grupos establecidos con mayor antigüedad y residencia legal tienden a contar con una red de contención y capital social que facilita por distintas vías el ejercicio de sus derechos, mientras aquellos de reciente arribo, y en situación más vulnerable, visualizan una débil concepción de sí mismos como sujetos de derechos -en gran medida por falta de información-, contando en algunos casos con el amparo de un conjunto de instituciones que, con base en la normativa vigente, definen mecanismos de presión para su exigibilidad (Pastoral migratoria, consulados, organizaciones de migrantes).

De esta manera, el ajuste entre la ciudadanía en términos normativos y en términos sustantivos radica más que en un problema de ampliación de derechos, en la superación de este conjunto de condiciones institucionales, culturales y sociales que limitan la realización práctica de la misma.

\section{Referencias}

Arango, J. (2000). Enfoques conceptuales y teóricos para explicar la migración. Revista Internacional de Ciencias Sociales, 165, 33-47.

Badaró, M. (2006). La conciencia y la ley: La cuestión migratoria en las prácticas de agencias estatales y organismos no gubernamentales en la ciudad de Buenos Aires. En A. Grimson y E. Jelín (Comps.), Migraciones regionales hacia la Argentina: Diferencia, desigualdad y derechos (pp. 207-235). Buenos Aires, Argentina: Prometeo.

Belil, M. (2017). La gestión local de la inmigración: La perspectiva política. IV Seminario Inmigración y Europa. Inmigración y Gobierno Local. Experiencias y Retos. Recuperado de https://www.cidob.org/media2/publicacions/monografias/ iv_seminari_migracions/05_belil 
Benencia, R. (2012). Los inmigrantes bolivianos en el mercado de trabajo de la horticultura en fresco en la Argentina. En El impacto de las migraciones en Argentina (pp. 153-234). Buenos Aires, Argentina: Organización Internacional para las Migraciones.

Caggiano, S. (2017). La nueva política migratoria argentina: control y exclusión. Megafón, (14), 1-3.

Camós, I. (2017). La participación de los gobiernos locales en las políticas de inmigración: Las competencias municipales en materia de inmigración. IV Seminario Inmigración y Europa. Inmigración y Gobierno Local. Experiencias y Retos. Recuperado de https://www.cidob.org/media2/publicacions/monografias/iv_seminari_migracions/03_camos

Castaño, Á. (2009). Inserción social y residencialidad de los inmigrantes en las áreas urbanas de Sevilla y El Ejido Ángeles. Áreas. Revista Internacional de Ciencias Sociales, (28), 89-109.

Centro de Estudios Interdisciplinarios en Problemáticas Internacionales y Locales (CEIPIL). (2011). Las organizaciones de inmigrantes latinoamericanos en el interior de la provincia de Buenos Aires y el acceso a derechos sociales. Tandil y Pinamar como estudios de caso (Informe presentado ante el Observatorio Social Legislativo de la Honorable Cámara de Diputados de la provincia de Buenos Aires). Tandil, Buenos Aires, Argentina: unCPBA.

Centro de Estudios Interdisciplinarios en Problemáticas Internacionales y Locales (CEIPIL). (2013a). Derechos sociales, inmigración y discriminación en el interior de la provincia de Buenos Aires (Informe Técnico presentado por el CEIPIL (Universidad Nacional del Centro de la Provincia de Buenos Aires) al Instituto contra la Discriminación, la Xenofobia y el Racismo). Argentina: Ministerio de Justicia y Derechos Humanos de la Nación.

Centro de Estudios Interdisciplinarios en Problemáticas Internacionales y Locales (CEIPIL). (2013b). Mapa contra la discriminación de la región sur de la provincia de Buenos Aires. Tandil, Buenos Aires, Argentina: CEIPIL (UNCPBA), INADI.

Centro de Estudios Legales y Sociales (CELS), Federación Internacional de Derechos Humanos (FIDH). (2011). Argentina. Avances y asignaturas pendientes en la consolidación de una política migratoria basada en los derechos humanos. Recuperado de https://www.cels.org.ar/web/wp-content/uploads/2011/02/Argentina.-Avances-y-asignaturas-pendientes-en-la-consolidacion.pdf

Ciarallo, A. M. (2007). Tiempos, espacios e identidades. Migrantes bolivianos hortícolas en una localidad del Alto Valle de Río Negro. $\mathrm{V}^{\circ}$ Jornadas Interdisciplinarias de Estudios Agrarios y Agroindustriales. Facultad de Ciencias Económicas, Universidad de Buenos Aires, Argentina.

Correa, V. A. (2004). La nueva ley de migraciones y la participación de las organizaciones de la sociedad civil. En R. Giustiniani (Comp.), Migración: Un derecho humano (pp. 175-179). Buenos Aires, Argentina: Prometeo.

Domenech, E. (2008). La ciudadanización de la política migratoria en la región sudamericana: Vicisitudes de la agenda global. En S. Novick (Comp.), Las migraciones en América Latina. Políticas, Culturas y Estrategias (197- 214). Buenos Aires, Argentina: Catálogos.

Fuks, A., Jait, A., Harrington, M. E., Pérez-Panelli, S. y Rovere, M. (2008). Migraciones y salud. Revista PoSIbles, (2), 20-30. 
Garcés, A. (2014). Contra el espacio público: Criminalización e higienización en la migración peruana en Santiago de Chile. EURE, 40(121), 141-162.

Goldberg, A. (2014). Inmigración, políticas de salud pública y tuberculosis en clave antropológica comparativa: Los casos de España/Barcelona y Argentina/Buenos Aires. Anuario Digital Cemi, 33-62.

Guber, R. 2006. La etnografía. Método, campo y reflexividad. Bogotá, Colombia: Grupo Editorial Norma.

Habermas, J. (1998). Reconciliación mediante el uso público de la razón. En Habermas y J. Rawls, Debates sobre el liberalismo Político. (pp. 41-71) Barcelona, España: Paidós.

Hernádez, R., Fernández-Collado, C. y Baptista, P. (2006). Metodología de la investigación (4 ed.). México, Distrito Federal: McGraw-Hill Interamericana.

Instituto de Políticas Públicas en Derechos Humanos del Mercosur (IPPDH), Defensoría del Pueblo de la Provincia de Buenos Aires. (2014). Acceso a derechos de las personas migrantes en la provincia de Buenos Aires. Argentina: Autor.

Instituto Nacional de Estadísticas (INE), Ministerio de Relaciones Exteriores (Minrel-Dicoex). (2017). Segundo Registro de Chilenos en el Exterior ¿̇Cuántos son, dónde están y cómo son los chilenos? Recuperado de http://www.registrodechilenos.cl/ descargas/segundo-registro-de-chilenos-en-el-exterior.pdf

Instituto Nacional de Estadísticas y Censos (INDEC). (2010). Censo Nacional de Población, Hogares y Vivienda 2010. Recuperado de https://www.indec.gov.ar/nivel4_default.asp?id_tema_1=2\&id_tema_2=41\&id_tema_3=135

Jelín, E. (2007). Introducción. En E. Jelín (Dir.), Salud y migración regional. Ciudadanía, discriminación y comunicación intercultural (pp. 7-14). Buenos Aires, Argentina: Ides.

Kraser, M. B. y Ockier, C. E. (2007). La población boliviana en la localidad de General Daniel Cerri. Práctica cultural y accionar de los agentes en la horticultura. Comunicación presentada en las V Jornadas Interdisciplinarias de Estudios Agrarios y Agroindustriales, Facultad de Ciencias Económicas, Universidad de Buenos Aires, Argentina.

Liberona, N. y Mansilla, M. A. (2017). Pacientes ilegítimos: Acceso a la salud de los inmigrantes indocumentados en Chile. Salud Colectiva, 3(13), 507-520.

López, A. M. (2005). Inmigrantes y Estados: La respuesta política ante la cuestión migratoria. Barcelona, España: Anthropos.

López, R. y Deslauriers, J. P. (2011). La entrevista cualitativa como técnica para la investigación en Trabajo Social. Margen, (61), 1-19. Recuperado de http://www. margen.org/suscri/margen61/lopez.pdf

Mármora, L. (2002). Las políticas de migraciones internacionales. Buenos Aires, Argentina: Paidós.

Mezzadra, S. y Nielson, B. (2014). Fronteras de inclusión diferencial. Subjetividad y luchas en el umbral de los excesos de justicia. Papeles del CEIC, 2(113). Recuperado de http://dx.doi.org/10.1387/pceic.12980

Nicolao, J. (2013). Política migratoria: Legislación y prácticas profesionales en el ámbito de los derechos sociales. Revista de Trabajo Social Plaza Pública, 9(6), 119-141. Recuperado de http://revistaplazapublica.files.wordpress. com/2014/02/10.pdf 
Nicolao, J. (2014). La internacionalización de las políticas migratorias. Estudio de caso argentino (2003-2012) (Tesis doctoral). Universidad Nacional de San Martín, Buenos Aires, Argentina.

Organización Internacional para las Migraciones (OIM), Instituto de Políticas Públicas en Derechos Humanos del Mercosur (IPPDH). (2017). Migrantes regionales en la ciudad de San Pablo. Derechos políticos y sociales. Buenos Aires, Argentina: Autor.

Pereyra, B. (2005). ¿La unión hace la fuerza? Ciudadanía y organizaciones en el contexto de la migración. En Centro de Encuentros Cultura y Mujer (CECYM), Fundación Instituto de la Mujer, Cotidiano Mujer, Movimiento Pro Emancipación de la Mujer (мемн), Red de Educación Popular entre Mujeres (REPEM), Migraciones, globalización y género. En Argentina y Chile (pp. 57-78). Buenos Aires, Argentina: Autor.

Reyes, P. y Hernández, A. (2008). El estudio de caso en el contexto de la crisis de la modernidad. Cinta de Moebio, (32), 70-89.

Santamarina, C. (2016). El acceso de los inmigrantes limítrofes al primer nivel de atención de la salud. Estudio de caso de la ciudad de Tandil (Tesis). Universidad Nacional del Centro de la Provincia de Buenos Aires, Tandil. Argentina.

Stefoni, C. (2009). Inmigrantes en Chile: Una integración diferenciada al mercado laboral. En VV. AA., Migración y políticas sociales en América Latina (pp. 81-107). Río de Janeiro, Brasil: Sopla.

Stefoni, C. (2011). Ley y política migratoria en Chile: la ambivalencia en la comprensión del migrante. En B. Feldman-Bianco, L. Rivera, C. Stefoni y M. I. Villa (Comps.), La construcción social del sujeto migrante en América Latina: Prácticas, representaciones y categorías (pp. 79-110). Quito, Ecuador: Clacso, Flacso, Universidad Alberto Hurtado.

Suárez-Navaz, L. (2005). Ciudadanía y migración: ¿Un oxímoron? Punto de Vista, 4(1), 29-47.

Thayer, L. E. y Durán, C. (2015). Gobierno local y migrantes frente a frente: Nudos críticos y políticas para el reconocimiento. Revista del CLAD Reforma y Democracia, (63), 127-162.

Toranzos, R. (2014). Mantenimiento y cambio de lengua: El quechua entre inmigrantes bolivianos residentes en Bahía Blanca (Tesis). Universidad Nacional del Sur, Bahía Blanca, Argentina.

Torrecilla, A. (2014). Turismo cultural en Bahía Blanca: el aporte de las colectividades extranjeras como rasgo de singularidad de un destino (Tesis). Universidad Nacional del Sur, Bahía Blanca, Argentina.

Varela, G. (2005). Mujeres partidas: Análisis discursivo de historias de migración. En Centro de Encuentros Cultura y Mujer (СесYM), Fundación Instituto de la Mujer, Cotidiano Mujer, Movimiento Pro Emancipación de la Mujer (мемн), Red de Educación Popular entre Mujeres (repem), Migración, globalización y género en Argentina y Chile (pp. 79-147). Buenos Aires, Argentina: Autor. 


\section{Material legislativo}

Decreto de Necesidad y Urgencia $\mathrm{N}^{\circ}$ 70. Modificación Ley $\mathrm{N}^{\circ}$ 25.871. Boletín Oficial. 30 de enero de 2017. República Argentina. Poder Ejecutivo Nacional.

Decreto $\mathrm{N}^{\circ} 616$ Reglamentación de la Ley de Migraciones $\mathrm{N}^{\circ} 25.871$ y sus modificatorias.

Boletín Oficial. 6 de mayo de 2010. República Argentina. Poder Ejecutivo Nacional.

Ley de Educación Provincial No 13.688. Boletín Oficial. 10 de julio de 2007. República Argentina. Senado y Cámara de Diputados de la Provincia de Buenos Aires.

Ley de Migraciones $\mathrm{N}^{\circ}$ 25.871. Boletín Oficial. 21 de enero de 2004. República Argentina. Senado y la Cámara de Diputados de la Nación.

Julieta Nicolao

Argentina. Doctora en Ciencia Política por la Universidad Nacional de General San Martín (Argentina). Fue becaria doctoral y posdoctoral del Consejo Nacional de Investigaciones Científicas y Técnicas (2009-2016). Actualmente se desempeña como Investigadora Asistente de la Comisión de Investigaciones Científicas de la Provincia de Buenos Aires. Es miembro de la Planta Estable del Centro de Estudios Interdisciplinarios en Problemáticas Internacionales y Locales (CEIPIL) de la UNICEN. Líneas de investigación: migraciones internacionales y políticas migratorias en Argentina. Entre sus publicaciones recientes: Migraciones regionales y derechos a escala local. Reflexiones en torno al Municipio de General Pueyrredón. (2017). Revista de Integración Regional Densidades, (22), 113-147. 